\title{
Ostrich Farming: A New Turn in Poultry Industry of Pakistan
}

\author{
Ghulam Abbas $^{1, *}$, Sultan Mahmood ${ }^{2}$, Muhammad Sajid ${ }^{3}$, Yasir Ali ${ }^{4}$ \\ ${ }^{1}$ Department of Livestock Production and Management (Poultry Science Wing), Riphah College of Veterinary Sciences, Riphah \\ International University, Lahore, Pakistan \\ ${ }^{2}$ Institute of Animal Sciences, University of Agriculture, Faisalabad, Pakistan \\ ${ }^{3}$ Department of Anatomy, Riphah College of Veterinary Sciences, Riphah International University, Lahore, Pakistan \\ ${ }^{4}$ Department of Plant Pathology, University College of Agriculture, University of Sargodha, Pakistan
}

Copyright $\bigcirc 2017$ by authors, all rights reserved. Authors agree that this article remains permanently open access under the terms of the Creative Commons Attribution License 4.0 International License

\begin{abstract}
Ostriches are the biggest ratite in the world. Their wild changing behaviour helps us to consider them as domestic birds. Ostriches can reach adult height 6-10 feet tall in between 1.5 to 2 years of age and their head may reach $1.8-2.75 \mathrm{~m}$ above the ground due to large legs. These largest vertebrate only run in case of any danger and can run at a speed of 65-70 kilometer per hour. Presently there are four subspecies of ostriches which are limited to Africa. Ostriches can be reared on short grass plains and semi-arid desert areas. Meat of ostriches is very healthy for humans' consumption. Ostrich birds produce red meat that is similar to deer meat or beef and the hide makes fine leather products. Frequency of mating may be low in confined environment. Mostly breeders are kept in group of trio (1:2); one male for two females. Ostriches can live on any cattle fodder; however during early six months of life they need special feeds for better growth. Ostriches may gain $1 \mathrm{Kg}$ body weight with only $3 \mathrm{Kg}$ food, unlike cattle which gain $1 \mathrm{Kg}$ body mass with $20 \mathrm{~kg}$ fodder. Ostrich may reach sexual maturity at about two to three years of age and lay 100eggs per season. Ostrich farming is now being done in the globe. Ostrich in Pakistan are now announced as a farm bird of commercial interest which is new turn in poultry industry of Pakistan.
\end{abstract}

Keywords Ostrich, Ratite, Red Meat, Cattle, Farming, Poultry Industry, Pakistan

\section{Introduction}

Ostriches are one of the oldest birds kept by mankind since the earliest recorded histories having existed as a species for over 40 million years. They are world's largest Ratite (species of flightless birds without keel bone; Struthio camelus) bird, the keel-less breastbone of ostriches resembles a raft and is actually a large cartilaginous plate [7]. An ostrich will reach adult height 6-10 feet tall in between 18 and 20 months of age with a growth rate $25 \mathrm{~cm}$ per month (7 $\mathrm{cm}$ per week) and 300-400 pounds in mass (Figure 1).

They can gain $80 \mathrm{~kg}$ body weight within 9 months and $100 \mathrm{~kg}$ in one year. Ostrich may also produce the $1.5 \mathrm{~kg}$ feathers at one year of age and its feathers are fluffy and symmetrical [4]. Other ratite birds are Emu (Dromaius novaehollandiae), Rhea (Rhea spp.), Cassowary (Casuarius spp.) and Kiwi, produce red meat that is similar to deer meat or beef and the hide makes fine leather products. A male ostrich is black with white wing tips and tail plumage called rooster and female ostrich light brown and gray plumage called hen. Female is smaller than rooster. Skin color fawn, dark brown, pink, red. Ostrich is the largest vertebrate and has ability to position his head to produce an image from in front of and below the eye [4]. 


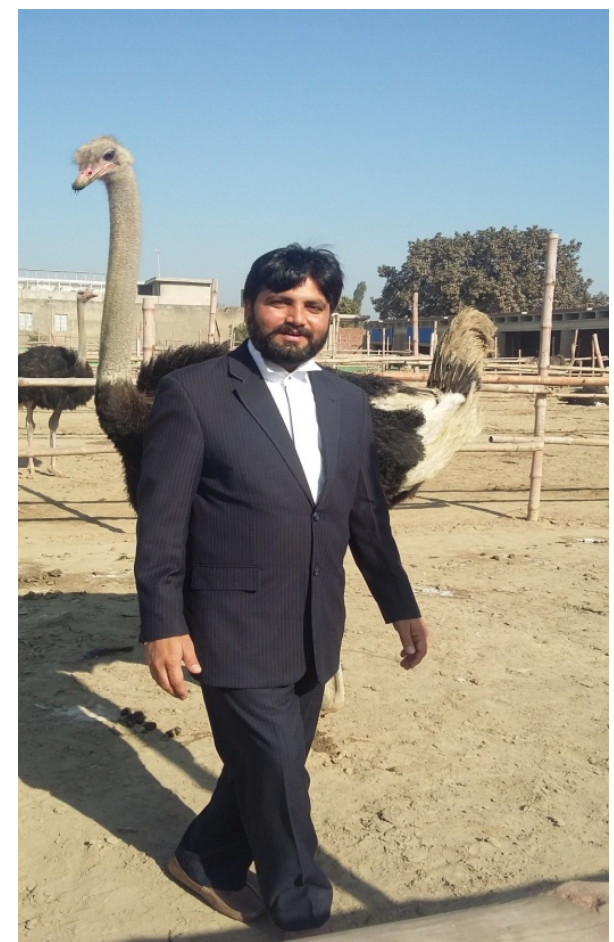

Figure 1. An adult ostrich with height 7 feet tall

\section{Comparative Anatomy and Physiology of Ostriches}

Ostriches have the longer limbs that provide help to attain great step lengths and step frequency [9]. On the other hand, compared to other terrestrial birds, such as rhea (Rhea spp.), emu (Dromaius novaehollandiae) and brown kiwi (Apteryx australis), ostriches relatively erect femurs increase the joint chain extension and symmetrical movement [1].Ostriches have two toes and powerful legs well adapted for running. Ostrich only runs in case of any danger and can run at a speed of 65 kilometer per hour [8]. Multi-jointed muscle tendon systems of ostrich are highly adapted for locomotion. The large amount of feed energy is saved in the tendons (See figure 3 ) which are used by the ostrich for running [2;19: 20].

The eyes of ostriches are $50 \mathrm{~mm}$ in diameter. The large blind spots on above and behind the head are considered to shade the eye [14]. Ostriches are able to see clearly for over $12 \mathrm{~km}$. Ostrich spends all the time walking around its environment and is unable to fly $[6 ; 2]$.The ostrich is the only ratite bird that has two toes in each foot whilst other ratites have three or four. Having three stomach, no gall bladder like horse, no crop secrete urine and feces separately, phallus (copulatory organ ) of an adult male is about 8 inches supported by lymphoid fluid instead of blood [8]. The ostrich has no substantial pectoral muscles and wings are poorly developed. Though ostrich can't fly, the presence of air sacs, pneumatized bones, strong pygostyle and presence of some wing bones give evidence that ostrich is evolved from flying ancestors [6].

Digestive tracts of the ostrich varied greatly and they have an ability to utilize substantial amount of dietary forage. In contrast to the digestive tract of chickens and turkeys, Ostriches have a relatively large true stomach (proventriculus) and gizzard, which has considerable food storage capacity [8]. The small intestine of ostriches is relatively short and the large intestine is very long, while the opposite is true for emus (Table 1). Ostriches possess relatively small ceca and have ability to utilize a good portion of fibrous substances provided in its diet after the appropriate [10: calhome, 1954).

\section{Sex Identification in Ostriches}

There is only one true species of ostrich (Struthio camelus) although several subspecies are recognized. Male ostrich of East Africa have pink or red skin and are often referred to a "red necks", while the more southern ostrich has blue skin and is referred to as "blue necks". The "African black is result of selective breeding from blue and red species and is shorter, smaller and has darker feathers than other species. The color of the neck is dependent on the presence of the male hormone testosterone. The color of the feathers is dependent on the presence or absence of the female hormone estrogen. Thus, castrated males will have normal feather color but not the skin color and immature or spayed females will have black feathers. Kicking is the major means of defense.

Ostriches can survive up-to 75 years, with 50 years being the average. The male is black, with white wing tips and tail plumes. The female is somewhat smaller than the male and duller in color, with light-brown and gray plumage $[4 ; 6]$ (See Figure 2). Young birds are mottled brown, and molt several times before attaining adult plumage.

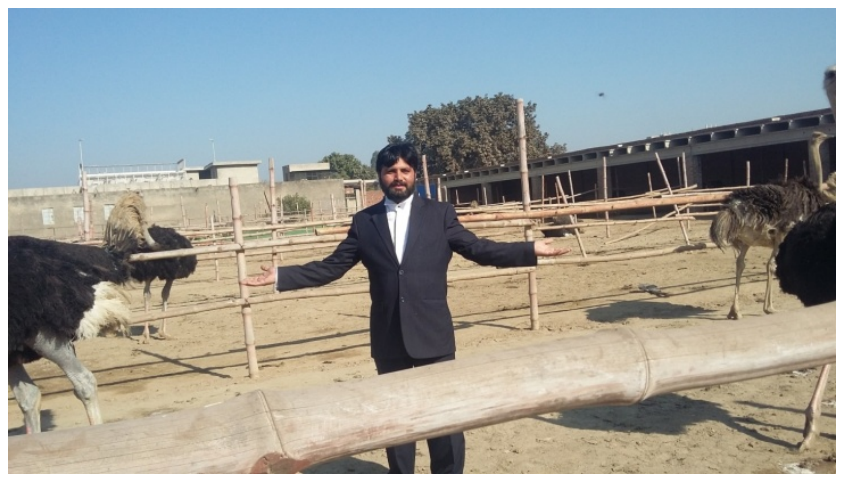

Figure 2. Adult male ostrich are solid black in color with white wing tips while the smaller females are brownish gray. Female is smaller than rooster.

\section{Sexual Maturity, Reproduction and Breeding Behavior}

The ostrich start breeding at about two to three years of 
age although males often mature later than females. Ostriches may continue for up to 25 years of age and produce maximum eggs at 6-11 years of age. Usually ostrich hens begin start fertile egg production at 2 to 3 years of age whilst males may take as long as 4 to 5 years to be functionally mature. In captivity, females may lay as many as 100 eggs in a season, although 20 to 40 are more common. Eggs are typically laid in late afternoon. Although mating may occur numerous times during the day, it is believed that a single mating may be effective for up to a week.

Ostriches will set up breeding "attachments," usually pairs or one male and two females. Ostriches will start laying eggs around the first of April and continue laying as late as the end of August. However this breeding season is from February to August in Pakistan. Eggs are laid about every other day, with an average of about 10-110 eggs are laid per year (breeding season). Eggs of Ostriches are whitish in color and weight of egg is $800-1800$ grams which is the smallest egg in relation to body size of the birds. Incubation of egg takes about $42-44$ days.

Courtship behavior includes complicated series of displays, dancing, vocalization and synchronous behavior, usually utilized to attract mating partner. The mating behavior of the male is quite elaborate with the male sitting on his hocks, moving his wings up and down while throwing his head from side to side. Receptive behavior of female includes bowing and ruffling her wings at her sides. Female walks with her head down, popping her beak and shaking her wings. Male usually makes a thumping sound and will inflate his neck area and create a loud booming noise. When approached, the female will sit, allowing the male to mount from the back. Male ostriches also get a lot of color during the breeding season.

Ostriches reproduce in monogamous or polygamous situations. Most breeders let the selection of mates occur naturally in a large communal pen and then separate the bonded pairs. The male "builds" (digs) the nest, typically a shallow depression in the earth. A male ostrich can become very aggressive during the breeding season and will guard the female, the nest and his territory. Both males and females sit on the nest.

The male digs a fissure in the ground by sitting and digging with his legs, pushing dirt backwards, forming the nest. Eggs are laid in these nests and the male usually sits on the eggs at night while the female incubates during the day. Wild clutches usually range from 8 to 14 eggs. Both parents are involved with the rearing of the young. Traditionally wearing of ostrich plumes often represented the status of nobility.

\section{Ostrich Farming an Innovative Turn in Poultry Industry}

Ostrich farming is now being done in the globe and in the last few years, ostrich farming has progressed dramatically. The world ostrich industry has achieved some economic stability. The first ostrich farm was founded in 1838 in South Africa, whilst commercial farm of ostrich was introduced in South Africa in 1863. Now this business has spread to about more than 100 countries. Some of the reasons for ostrich farming includes as it lays a good quality and heavy eggs. Proper male: female ratio may result in high fertility and a trio (1:2) may yield the maximum fertility and hatchability. However one may equally consider pairs (one male and one female), quads (one male and three females) or colonies (two or more males to two or more hens). The advantage of a colony is that the birds have more birds to choose from, in seeking a partner.

Ostrich can eat everything, Plants, Roots, Fruit, Insects, Lizards and small rodents. They also ingest Small rocks sand and clams to digest food. Ostrich have five world renowned breeds in world like: black neck ostrich, red neck ostrich, pink neck ostrich, blue neck ostrich and hybrid ostrich most popular is the black neck ostrich in the world.

The black neck ostrich adult male bird has a grey colored neck with black and white wing primaries and tail feathers. Different subspecies, however, might have different color patterns. Generally, female has white to light grey wing primaries and tail feathers with dull brown to grey color covering. Baby chicks; however are mottled brown, yellow, cream and orange with black quills on back while juvenile birds resemble the females, used primarily for expression during courtship or aggressive displays.

An ostrich produces $1 \mathrm{~kg}$ live weight on the cost of $4 \mathrm{~kg}$ balance feed and one $\mathrm{kg}$ fodder. Puberty starts in male at 3 years but females mature earlier at 2 years of age. Ostrich grows at a very high rate. Ostriches have the best FCR of any land animal in the world. This is because whatever it eats, it becomes part of its body.

Table 1. Comparative production performance of ostrich as compared to cattle

\begin{tabular}{|c|c|c|}
\hline & Ostrich & cattle \\
\hline Gestation/Incubation period & 42 & 280 \\
\hline Offspring per year & 40 & 1 \\
\hline Slaughter Age & 350 & 645 \\
\hline Meat (kg) & 2000 & 250 \\
\hline Leather (sq m) & 50 & 2.7 \\
\hline
\end{tabular}

In recent years ostrich farming is among the world's fastest growing multi products agricultural enterprise. Meat of ostrich is red meat like goat meat and has very low (in negligible concentration per unit mass) cholesterol. Ostrich meat market growing rapidly in the globe as its meat very healthy (contains less fat and cholesterol). Leather, eggs, feathers, oil and other products market are also under progress. It is estimated that ostrich farmers are meeting only 10 percent to the consumer demand in the world. 


\section{Ostrich Meat Suitable for Cardiac Patients and a New Taste in Food Industry}

Despite being poultry meat, ostrich meat is intensely red called red meat, and may be darker Lanza et al. [12]. However ostrich meat is enormously lean having intramuscular fat contents round about $2.3 \%$ in average most of which approximately $67 \%$ are easily digestible unsaturated fats having significantly high content of omega 3 $[5 ; 15]$. Energy contents of the diet are main factor considering the carcass fatty acid profile [12].

Ostrich meat is rich in Oleic acid (C18:1) contents, followed by palmitic acid (C16:0) and linoleic acid (C18:2n-6) [11;18). However chemical composition of meat is varies nutrition of the birds [22; 11], mainly by the energy: protein ratio 19: 20 19: 20 [23]

The average mineral level $(1.29 \%)$ in ostrich meat is higher than in chicken meat (1.17\%) [3]. Feeding the lucern or any fodder may increase total mineral content in ostrich meat as compared to birds fed only concentrate [16].

Age at slaughter and weight of the birds influence some meat quality traits, such as tenderness, juiciness and lipid contents etc. However these differences are not significant with gender. Parts yield may reach up to $42 \%$, depending on genetic background, rearing system, and slaughter techniques [3]. Ostrich meat is rich in Protein levels (28\%) and the most frequent amino acid is creatine [18].

As ostrich meat has very low fat content due to which it has a very unique flavor, characteristic of this species, being very tasty and mild. Ostrich meat is slightly sweet due to its higher muscle glucose content [17]. However low lipid content in ostrich meat confers low palatability to sausages and cured product $[19 ; 20 ; 21]$. Ostrich meat is very tender and easy to digest and to chew due to its high levels of unsaturated fat and its low collagen to protein ratio [3].

Ostrich meat has tendency to retain water during cooking [3], which ensures better texture (low shearing force) and juiciness. Meat color is also influenced by water holding capacity, as higher water content results in higher absorption of radiation and lower reflection, making the meat darker. Slaughter processing methods also affect meat quality of ostriches. It has been shown that the use of ozone for carcass chilling reduces its microbiological load.

\section{Ostrich Farming in Pakistan}

Pakistan is situated in the subtropical zone of Northern Hemisphere of the world where temperature usually remains well above the higher side of thermo-neutral zone $\left(25-37^{\circ} \mathrm{C}\right)$ for the greater part of the year (Anjum, 2000) especially during summer.

Being warm-blooded animals, ostriches maintain a nearly constant body temperature and are expert at behavioural thermoregulation to avoid overheating during hot weather
[13]. The environmental temperature of some parts in the region reaches up to $52^{\circ} \mathrm{C}$ [24]. On the other hand temperature during winter falls about even below $-7{ }^{\circ} \mathrm{C}$ in some parts of the country Ostriches can tolerate from -7 to 50 centigrade therefore are best animal under harsh climatic conditions. In this context environment of Pakistan is quite good for successful ostrich farming. Ostrich is newly emerging host birds in Pakistan rearing for meat, skin and feathers. Ostrich eat Lucerne fodder which is easily available in Pakistan.

Ostrich has been declared as domestic bird of commercial interest instead of free-living by the Government of Punjab in 2012. Ostrich in Pakistan are now announced as a farm bird. Pakistan has imported more than 14,000 ostrich form abroad and presently Pakistan has about 4000 ostriches with in more than 200 farms. Recently ostrich farming in Pakistan is multiplying rapidly to capture the large profit in the local and international market by launching its products. Government of Pakistan (especially Punjab Government) with close collaboration of academia (Avian research centre at Riphah College of Veterinary Sciences, Lahore, University of Veterinary and Animal Science Lahore, Arid Agricultural University, Rawalpindi) is playing its significant role in promoting ostrich farming in the country.

\subsection{Ostrich Production}

Baby chicks of ostrich can be maintained in a variety of suitable facilities. A small portable pen, 12 feet long, 4 feet wide and 2 foot high can be adequate for a number of chicks. Chicks are brought out to the pen after the temperature reaches above $60 \mathrm{~F}$ for sun bath. Shade and wind break may help to avoid extreme sun and wind. Immune system of ostriches is much stronger than livestock and poultry. However, being a good scientist/farmer you must care the chicks. Try to provide them a comfortable environment. Baby chicks should be brought indoors in the evening and maintained in a heated environment until at least 2 to 3 months of age. Temperature in indoor shelters should be maintained at least at $80 \mathrm{~F}$ and enough room should be provided to allow the birds to exercise to absorb the yolk. Do not provide feed at night however water should be available.

Growers (between 3 and 10 months of age) can be maintained in a similar, but larger facility as baby chicks. For growers shelter is not needed except in extremely cold areas. The amount of space per bird, for both indoor and outdoor facilities should be increased for this age bird as compared to that available for younger chicks. Outdoor pens can be of any type of substrate but ground cover such as grass, clover, or alfalfa is ideal. Grass should be kept at a closely chopped level, especially when grass begins to dry out or turn to seed, as impactions are more common at this time.

Pens and facilities for adults vary by far. Generally the recommended space that you need for an adult breeding pairs or trios is approximately 30 meters ( 32 yards) by 50 meters (55 yards) - a total of 1500 square meters. Recommended pen size for an ostrich trio varies from $1 / 4$ to $1 / 2$ acre. 
Females tend to mature slightly faster than males; different species may mature at different ages. More room can provide the better situation. Common fences and line of sight access to neighboring pairs is often desirable but may not be practicable with overly aggressive males.

Adult ostriches do not need indoor shelter once over 6 months of age, however, housing or shade is usually provided although not always utilized. If birds are familiar to their feed and water points in a shed they will be more easily confined when necessary and may construct the nest and lay indoors. Access for provisions for confinement for veterinary care should be considered at the time of construction and designing of the farm. Ostriches perform diverse maintenance activities (Sauer and Sauer, 1967) including Yawning, sleeping, waking. Fencing is dependent on personal preference and economics. Chain link is good but may result in problems related to leg and foot injures and is not easily climbed if escape from the pen by egg gatherers is necessary. Tubular "cattle" type fence is suitable and offer some benefits and others types of woven wire or bamboo fencing are routinely used.

Group pens consisting of several males and numerous females in larger acre area (similar to a natural situation) appears to provide some benefits with respect to fertility, more egg numbers, and extended laying periods. Several acres of enclosed pasture are needed for this type of operation.

\section{Conclusions}

Ostriches have a large number of adaptations that allow them to survive in harsh climatic conditions. Ostrich exhibits higher growth rate as compared to any other livestock, hence ostrich farming in geonetical conditions of Pakistan will appear be the beneficial to elicit a productive response and to reduce the gap between demand and supply of animal protein. However in the recent scenario, there is not a stable and significant demand for ostrich meat due to lack of knowledge and market availability in the country. Ostrich meat consumption may be increased especially among cardiac patients with the passage of time in the country. It is strongly needed to explore the solution for problems faced by the ostrich producers and improve the growth rate of ostriches. For this purpose Doctors Ostrich Company in Pakistan is interested in establishment of genetic improvement programs to exploit maximum genetic potential of ostrich birds.

\section{Acknowledgment}

This work is acknowledged to Professional Relief Organization and Care Link Trust UK.

\section{REFERENCES}

[1] Abourachid \& Renous. 2000. Abourachid A, Renous S. Bipedal locomotion in ratites (Paleognatiform): examples of cursorial birds. Ibis. 2000; 142:538-549.

[2] Alexander et al. 1979. Alexander RM, Maloiy GMO, Njau R, Jayes AS. Mechanics of running of the ostrich (Struthiocamelus) Journal of Zoology.1979; 187:169-178.

[3] Balog, A., A. A. Mendes, I. C. L. Almeida Paz, M. C. Silva, S. E. Takahashi and C. M. Komiyama. 2006. Rendimento de carcaça e avaliação da qualidadenda carne de avestruzes. Anais da Reunião Anual da Sociedade Brasileira de Zootecnia. João Pessoa, PB. Brasil.

[4] Brown, L. H., Urban, E.K. and Newman, K. 1982 Order Struthioniformes. In: The birds of Africa, Vol. I. Academic Press, London, pp.32-37.

[5] Cooper, R. G. and O.Horbanczuk.2002. Anatomical and physiological characteristics of ostrich (Struthio camellus var. domesticus) meat determinate its nutritional importance for man. Anim. Sci. J. 73:167-173.

[6] Cramp, S., Simmons, K. E. L., Ferguson LEES, I.J., Gillmor. Hollom, P.A.D., Hudson, R., Nicholson, E. M., Ogilivie, M.A., Olney, P.J.S., Voous, K.H and Wattel, J. 1997. Order Struthioniformes. In: Handbook of the Birds of Europe, the Middle East and North Africa. The Birds of the Western Paleactic, Vol. 1, Ostrich to Ducks. Oxford University Press, Oxford, pp. 37-41.

[7] Deeming, D. C. and C. R. Angel. 1996. Introduction to the ratites and farming operations around the world. In: Deeming, D.C. (ed.) Improving our Understanding of Ratites in a Farming Environment. Ratite Conference, Oxfordshire, UK, pp. 1-4.

[8] Fowler, M. E., 1991. J. of Zoo and Wildlife Med. 22:204-227.

[9] Gatesy \& Biewener. 1991. Gatesy SM, Biewener AA. Bipedal locomotion: effects of speed, size and limb posture in birds and humans. Journal of Zoology. 224: 127-147. doi:10.1111/j.1469-7998.1991.tb04794.x

[10] Herd, R.M., and T.J. Dawson, 1984. Physiol. Zool. 57:70-84.

[11] Hoffman, L. C. and F. D. Mellet. 2003. Quality characteristics of low fat ostrich meat patties formulated with either pork lard or modified corn starch, soya isolate and water. Meat Science. 65:869-875

[12] Lanza, M., V Fasone, Galofaro V, D Barbagallo, M,Bella and P. Pennisi. 2004. Citrus pulp as an ingredient in ostrich diet: effect on meat quality. Meat Science; 68:269-275.

[13] Louw, G.N. (1972) The role of advective fog in the water economy of certain Namib Desert animals. Symposium of the Zoological Society London 31:297-314.

[14] Martin, G.R. and Katzir, G. (1995) Visual fields in ostriches. Nature 374:19-20.

[15] Matosses J. 1999. Caracterització nutricional de la carn dels estruços criats a Catalunya. Catalunya: Escola Superior 'AgricuItura de Barcelona. Trabajo final de carrera.

[16] Nitzan R., D. Barkai, Z. Nitzan and S. Landau.2002. Intake, growth and carcass characteristics of young ostriches given concentrates with and without pasture. Anim Sci. 74:71-79. 
[17] Paleari, M. A., S. Camisasca, G .Beretta, P. Renon, P. Corisco, G. Bertolo and G. Crivelli. 1998. Ostrich Meat: Physico-chemical characteristics and composition with turkey and bovine meat. Meat Science. 48:205-210.

[18] Sales, J., J. P. Hayes.1996. Proximate, amino acid and mineral composition of ostrich meat. Food Chemistry. 56: 167-170

[19] Schaller, N. U., B. Herkner, R. Villa, P. Aerts. 2009. The intertarsal joint of the ostrich (Struthio camelus): Anatomical examination and function of passive structures in locomotion. J Anat. 214(6):830-47.

[20] Schaller, N. U., D'Août K, R. Villa, B. Herkner, P. Aerts. 2011. Toe function and dynamic pressure distribution in ostrich locomotion. J Exp Biol.1; 214(Pt 7):1123-30.

[21] Van Jaarsveld, F. P., R. J. Naude, W. Oelofsen. 1998. Effect of chemical and physical dry-curing parameters on cathepsins B,
$\mathrm{H}$ and $\mathrm{L}$ from ostrich muscle. Meat Science. 50:223-233.

[22] Van Schalkwyk, S. J., L. C. Hoffman, S. W. P. Cloete, and F. D Mellett. 2005. The effect of feed withdrawal during lairage on meat quality characteristics in ostriches. Meat Science. 9:647-651.

[23] Van Schalkwyk, S. J., S. W. P. Cloete, L. C. Hoffman, T. S. Brand, Z. Brand and H. Lambrechts. 2002. The effect of dietary energy and protein levels on meat quality. Proceedings of the 2nd Joint Congress of the Grassland Society of Southern Africa and the South African Society of Animal Science, May 13; Christiana. p.84.

[24] Vidal, J. and D. Walsh. 2010. "Temperatures reach record high in Pakistan". guardian.co.uk (London). Retrieved 21 July 2010. Accessed on http://www.theguardian.com/world/2010/jun/01/pakistan-rec ord-temperatures-heatwave. 